\title{
Importância dos sistemas agroflorestais na composição de renda de agricultores familiares: estudo de caso no município de Belterra, Pará
}

\author{
Darielly Melize Carneiro COSTA ${ }^{1}$, Daniela PAULETTO ${ }^{1 *}$ \\ ${ }^{1}$ Universidade Federal do Oeste do Pará, Santarém, PA, Brasil. \\ *E-mail: paulettoflorestal@gmail.com \\ (ORCID: 0000-0003-3173-6240; 0000-0003-1855-6077)
}

\begin{abstract}
Recebido em 13/01/2020; Aceito em 31/01/2021; Publicado em 24/02/2021.
RESUMO: O Sistema Agroflorestal (SAF) é uma forma de diversificar a produção ao utilizar várias atividades e culturas em uma mesma área, envolvendo culturas agrícolas, essências florestais e, em alguns casos, envolvendo atividade pecuária. A análise econômica de projetos é uma atividade detalhada que requer elaborar planilhas de receitas e despesas de todas as atividades por meio do acompanhamento da produtividade de cada componente do sistema. Este estudo teve como objetivo realizar uma avaliação econômica de dois sistemas agroflorestais e avaliar sua importância financeira para os produtores. O estudo foi realizado em dois sistemas agroflorestais localizados no município de Belterra-PA nos anos de 2015 a 2017. A coleta de dados junto aos produtores foi baseada em entrevistas, com aplicação de questionário. No SAF 1 verificou-se que $96 \%$ da renda é oriunda da pimenta-do-reino, equivalendo a um total de $\mathrm{R} \$ 50.135,46$. O SAF 2 segue a mesma tendência de rentabilidade do SAF 1, sendo a pimenta-do-reino a cultura que impulsionou economicamente este sistema, com a produção em grãos, correspondendo a R $\$ 29.744,00$ (66\% da renda total do SAF 2). Os maiores custos nos SAFs 1 e 2 foram atribuídos a aquisição de insumos (NPK, esterco de galinha, esterco de gado e materiais para irrigação diversos) para o cultivo da pimenta-do-reino. Ressalta-se o uso de mão de obra, com preparo da área e tratos culturais, foi intenso nas duas propriedades, correspondendo a mais de $60 \%$ do total dos custos totais nos dois SAFs. O rendimento financeiro com atividades exercidas além do cultivo e manutenção dos SAFs 1 e 2 diversificam e complementam a remuneração dos produtores. Considera-se que os SAFs 1 e 2 são de extrema importância para os produtores avaliados, uma vez que geram renda e contribuem para a segurança alimentar e subsistência das famílias. O acompanhamento mensal, para aplicação de questionário de monitoramento da renda, mostrou ser viável a obtenção de dados confiáveis perante o estreitamento de confiança e atenção as atividades de exercidas.
\end{abstract}

Palavras-chave: agricultura familiar, viabilidade econômica, cultivo consorciado.

\section{Income composition by family farmers and the importance of agroforestry systems: case study in Belterra, Pará, Brazil}

\begin{abstract}
The Agroforestry System (SAF) is a way to diversify production by using various activities and crops in the same area, involving agricultural crops, forest essences and, in some cases, involving livestock activities. Economic analysis of projects is a detailed activity that requires preparing income and expense spreadsheets for all activities by monitoring the productivity of each component of the system. This study aimed to carry out an economic evaluation of two agroforestry systems and to assess their financial importance for producers. The study was carried out in two agroforestry systems located in the municipality of BelterraPA in the years 2015 to 2017. The data collection from the producers was based on interviews, with the application of a questionnaire. In SAF 1, it was found that $96 \%$ of the income comes from black pepper, equivalent to a total of $\mathrm{R} \$ 50,135.46$. SAF 2 follows the same profitability trend as SAF 1 , with black pepper being the crop that economically boosted this system, with grain production, corresponding to $\mathrm{R} \$ 29,744.00$ ( $66 \%$ of SAF 2's total income). The highest costs in SAFs 1 and 2 were attributed to the acquisition of inputs (NPK, chicken manure, cattle manure and various irrigation materials) for the cultivation of black pepper. The use of labor, with preparation of the area and cultural treatments, was intense in both properties, corresponding to more than $60 \%$ of the total total costs in the two SAFs. The financial income from activities carried out in addition to the cultivation and maintenance of SAFs 1 and 2 diversify and complement the remuneration of producers. SAFs 1 and 2 are extremely important for the producers evaluated, since they generate income and contribute to food security and subsistence for families. The monthly follow-up, for the application of an income monitoring questionnaire, proved to be viable to obtain reliable data in view of the strengthening of confidence and attention to the activities performed.
\end{abstract}

Keywords: family farming; economic viability; intercropping cultivation.

\section{INTRODUÇÃO}

Em sua maioria a região amazônica não possui características fisiográficas e edafoclimáticas ideais para práticas agrícolas convencionais. Neste âmbito, buscam-se alternativas para se reverter essa situação que tragam para a Amazônia o desenvolvimento sustentável com custos sociais, 
econômicos e ambientais mínimos e possibilidades econômicas para essas famílias (SERRÃO; HOMMA, 1991).

Segundo Abdo et al. (2008) os sistemas agroflorestais (SAFs) constituem-se sistemas de uso e ocupação do solo vistos como uma técnica alternativa de cultivo e uso da terra, onde plantas lenhosas perenes (árvores, arbustos, palmeiras) são manejadas em associação com plantas herbáceas, culturas agrícolas e/ou forrageiras e/ou em integração com animais, em uma mesma unidade de manejo, de acordo com um arranjo espacial e temporal, com alta diversidade de espécies e interações ecológicas entre estes componentes. Com isso estes sistemas diversificam a produção ao utilizar várias atividades e culturas em uma mesma área, visando à maximização de renda (SOUZA et al., 2007) e geram receitas para o agricultor, contribuindo para minimizar perdas com possíveis prejuízos de safras (OLIVEIRA, 2017).

A característica mais importante de um SAF deve ser a estabilidade ou sustentabilidade ecológica. Esta sustentabilidade resulta da diversidade biológica promovida pela presença de diversas espécies vegetais e/ou animais, que exploram nichos diversificados dentro do sistema. A multiestratificação de espécies de diferentes usos, que exploram os perfis verticais e horizontais da paisagem nos SAF, otimizam o máximo aproveitamento da energia solar (MACEDO, 2000).

Estudos na Amazônia atestam a rentabilidade econômica dos SAFs com a associação de espécies agrícolas, florestais e frutíferas (SILVA, 2016; OLIVEIRA, 2017; ARCOVERDE, 2008; MENDES, 2003), mas, no entanto, por serem cultivos mais complexos apresentam mais riscos do ponto de vista econômico (BENTES-GAMA et al., 2005). Dessa forma o estudo econômico de SAFs se configura uma ferramenta importante para tomada de decisão quanto a arranjos de espécies e investimentos nesta modalidade.

A análise econômica de projetos é uma atividade detalhada que requer elaborar planilhas de receitas e despesas das atividades. As receitas do projeto são medidas através do cálculo da produtividade de cada componente do sistema (agrícola, florestal ou animal), sabendo que as receitas advêm de produtos comercializados dos SAFs. Nestes sistemas podem ocorrer espécies que geram um ou mais produtos, além de produtos que vem de uma ou mais espécies, e que precisam ser analisados e tratados de forma adequada (ARCO-VERDE; AMARO 2014).

A rentabilidade das áreas e o bem-estar dos agricultores se dá devido a melhores condições de vida dessas populações, bem como ao potencial econômico de espécies cultivadas na Amazônia, as escolhas para introdução em SAF e as oportunidades de mercado e preços de cada uma. Com isso, justifica-se fazer análises econômicas de SAFs, observando seus produtos e sua comercialização dentro da agricultura familiar e a rentabilidade para este grupo.

Este estudo teve como objetivo realizar uma avalição econômica de dois sistemas agroflorestais e sua importância para os produtores avaliados.

\section{MATERIAL E MÉTODOS}

\section{1. Áreas de estudo}

As áreas em análise situam-se no município de Belterra na mesorregião do Baixo Amazonas no estado do Pará. De acordo com a classificação de Köppen o clima no município de Belterra é do tipo $A m$, com altitute média de 130 metros, com estação menos chuvosa nos meses de agosto a dezembro e precipitação média anual de 2.200 milímetros
(ALVARES et al., 2013).

As médias climáticas para o período estudado foram de $27^{\circ} \mathrm{C}$ de temperatura (máximas de $34,5^{\circ} \mathrm{C}$ e mínimas de $22^{\circ} \mathrm{C}$ ) de acordo com os dados disponibilizados pelo Instituto Nacional de Meteorologia (INMET, 2016). A caracterização da vegetação típica da área é de Floresta Ombrófila Densa (CORDEIRO, 2004).

O estudo foi realizado em dois SAFs (SAF1 e SAF2) inseridos em propriedade de agricultores familiares no município de Belterra, Pará. O SAF1 localiza-se nas

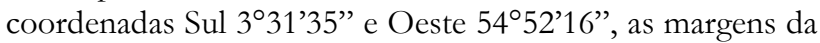
Rodovia BR 163. O plantio possui uma área de 1 hectare inserido em uma propriedade de 100 hectares. O histórico de uso da área onde atualmente está instalado o SAF1, baseia-se no corte raso da vegetação, queima e criação de gado durante cinco anos. No ano de 2012 foi implantado o SAF composto por cumaru (Dipteryx odorata (Aublet.) Willd.), cupuaçu (Theobroma grandiflorum Willd.ex Spreng. Schum), açaí (Euterpe oleracea Mart.), graviola (Annona muricata), banana (Musa sp.) e pimenta-do-reino (Piper nigrum L.). Ressalta-se que houve plantação de macaxeira (Manihot sp.) nos primeiros dois anos nas entrelinhas do plantio perene.

O SAF 2 está localizado no travessão Galiléia nas

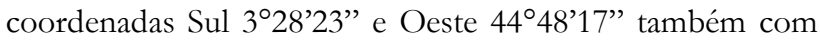
acesso pela Rodovia Cuiabá-Santarém (BR 163), em uma propriedade de 100 hectares. No ano de 2012 foram implantados 1 ha de forma consorciada dos seguintes cultivos: cumaru (Dipteryx odorata (Aublet.) Willd.), andiroba (Carapa guianensis Aubl.), pimenta-do-reino (Piper nigrum L.), açaí (Euterpe oleracea Mart.) e moringa (Moringa oleifera Lam.), sendo que nos três primeiros anos houve plantações anuais de macaxeira (Manihot sp) e abacaxi (Ananas sp). Nos 15 anos que antecederam a implementação do sistema agroflorestal a área foi utilizada para criação de gado de corte.

Para a obtenção de dados para esta pesquisa realizou-se acompanhamentos mensais nas áreas de SAFs, iniciando em agosto de 2015, durante dois anos. A coleta de dados junto aos produtores foi baseada em entrevistas, com aplicação de questionário (Apêndice A) para acompanhamento da produção do SAF.

As informações de campo foram registradas no software Excel 2013, dando suporte para a catalogação da entrada de dados para a realização da análise financeira e cálculos dos custos dos SAF.

A metodologia utilizada para a realização da análise financeira considerou as atividades de mão-de-obra, os insumos requeridos para os SAF, o custo da manutenção dos sistemas e a venda dos produtos.

\section{RESULTADOS}

Na Tabela 1 observa-se a distribuição da renda acumulada em períodos (chuvoso e seco) considerando a distribuição das chuvas no município de Belterra, onde observa-se que os maiores valores estão concentrados no período chuvoso, indicando que a sazonalidade influencia na produtividade dos sistemas e na renda dos produtores.

O SAF 1 apresentou renda média mensal de $\mathrm{R} \$ 1.686,66$ e $R \$ 1.683,66$ nos anos de 2016 e 2017, respectivamente, totalizando uma renda acumulada em 2 anos de $\mathrm{R} \$ 52.293,45$ conferindo medianas com os seguintes valores: ago/dez 2015 $=816,66$, jan $/$ jul 2016 $=1166,66$, ago $/ \mathrm{dez} 2016=226,66$, jan $/$ ago $2017=193,33$. Este produtor, além da produção no sistema agroflorestal, exerce atividades complementares como venda de ovos de galinha e polpa de maracujá de 
plantios em outras áreas externas ao SAF.

Tabela 1. Renda acumulada em sistemas agroflorestais por período (seco e chuvoso) no município de Belterra, Pará.

Table 1. Accumulated income in agroforestry systems per period (dry and rainy) in the municipality of Belterra, Pará.

\begin{tabular}{|c|c|c|c|c|}
\hline \multirow{2}{*}{ Ano } & \multirow{2}{*}{ Mês } & \multirow{2}{*}{ Período } & SAF1 & SAF2 \\
\hline & & & \multicolumn{2}{|c|}{ Renda (R\$) } \\
\hline 2015 & Ago a dez & Seco & $18.584,11$ & $28.000,00$ \\
\hline 2016 & Jan a jul & Chuvoso & $16.833,33$ & $4.285,00$ \\
\hline 2016 & Ago a dez & Seco & $3.406,66$ & $1.500,00$ \\
\hline 2017 & Jan a jul & Chuvoso & $9.061,33$ & $9.744,00$ \\
\hline 2017 & Jul a Ago & Seco & $4.408,00$ & $1.610,00$ \\
\hline & & Soma & $52.293,45$ & $45.139,00$ \\
\hline
\end{tabular}

O SAF 2 apresentou renda média mensal de $\mathrm{R} \$ 482,08$ e $\mathrm{R} \$ 1.419,25$ nos anos de 2016 e 2017, respectivamente resultando em mediana em ago/dez $2015=880,00, \mathrm{Jan} / \mathrm{ju}$ $2016=1435,00$, ago/dez $2016=1500,00$ e Jan/ago2017 $=$
1660,00. Este produtor exerce outras atividades agrícolas como venda de doces de frutas, de peixes, cultivo em monocultura de feijão, melancia e macaxeira e comercialização de mudas de açaí.

Quanto a renda mensal dos SAFs por hectare (Figura 1), observa-se que os valores oscilaram ao longo dos meses do período estudado (agosto/2015 a agosto/2017) sendo as maiores rendas registradas nos meses de agosto/2015, maio/2016 e maio/2017.

Os resultados dos SAFs 1 e 2 indicam um comportamento de certa forma semelhantes, visto que nos dois sistemas, os rendimentos mais elevados estão diretamente ligados a venda de pimenta-do-reino em estoque e seu valor de mercado ( $\mathrm{R} \$ 9,00$ a $\mathrm{R} \$ 25,00 / \mathrm{kg})$ no período estudado.

Quando avaliada a renda por espécie nos SAFs (Figura 2), observa-se em ambos, o protagonismo do cultivo e venda de grãos de pimenta-do-reino na composição da renda.

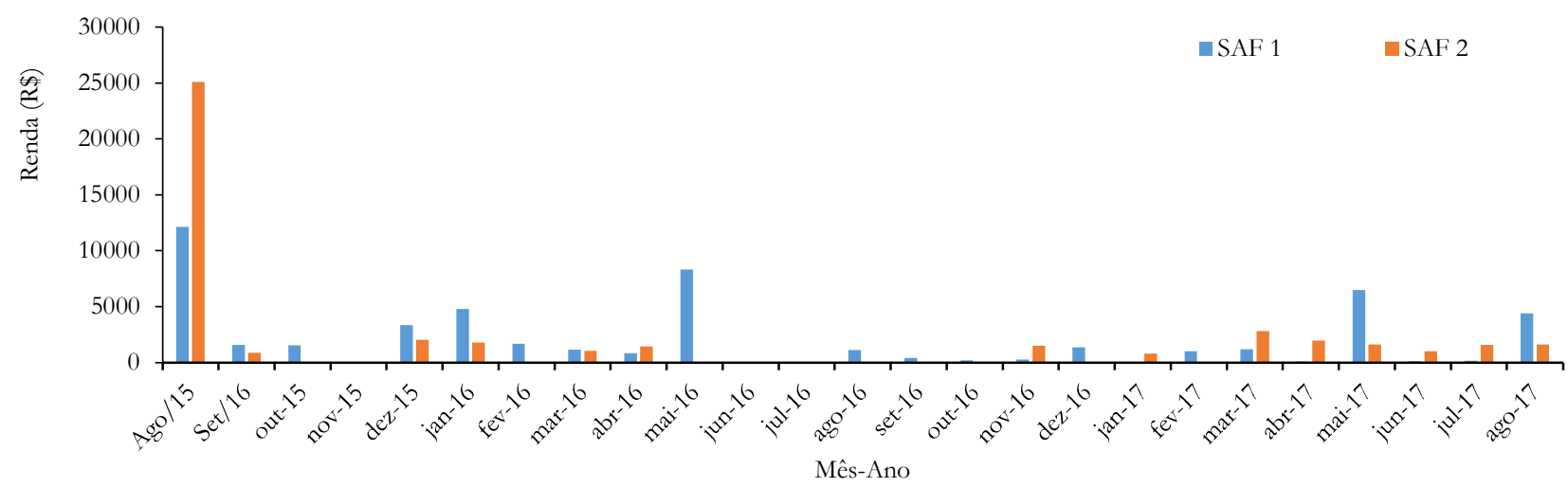

Figura 1. Renda mensal por ha dos SAFs 1 e 2 no período de agosto de 2015 a agosto de 2017, no município de Belterra, Pará. Figure 1. Monthly income per ha of SAFs 1 and 2 from August 2015 to August 2017, in the municipality of Belterra, Pará.

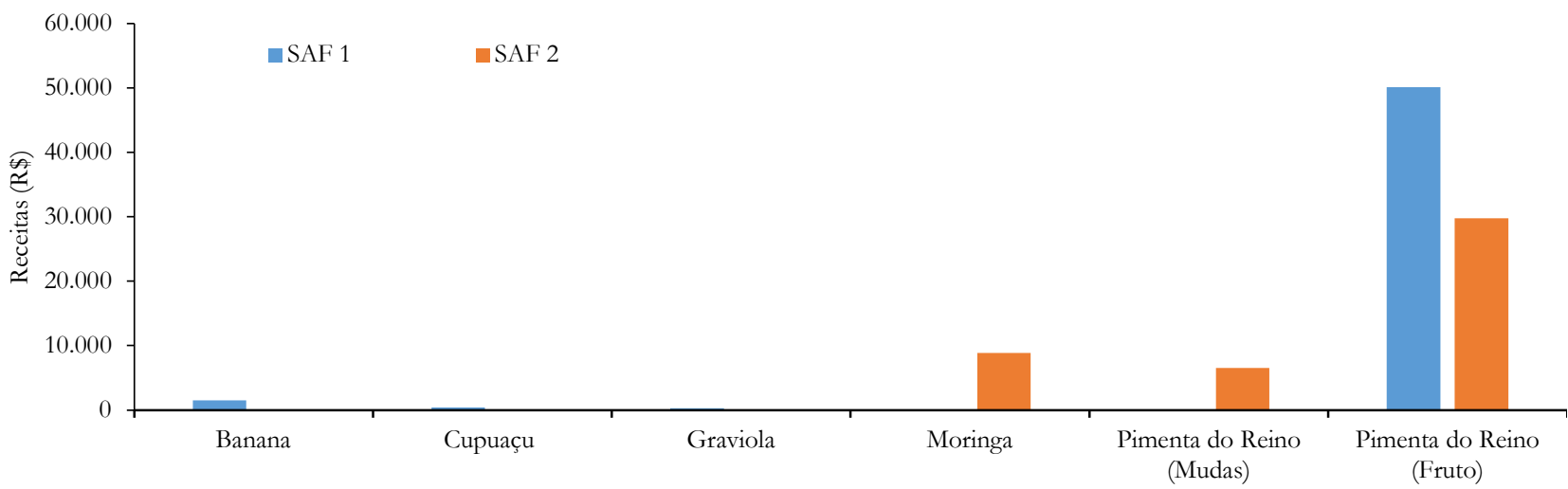

Figura 2. Renda acumulada das espécies por hectare em SAFs no município de Belterra no período de dois anos.

Figure 2. Accumulated species income per hectare in SAFs in the municipality of Belterra over a two-year period.

No SAF1 grande parte $(96 \%)$ da renda é oriunda da pimenta-do-reino, que equivaleu a um total de $\mathrm{R} \$ 50.135,46$ enquanto os demais produtos somaram $4 \%$ do faturamento, onde destaca-se a banana com uma renda de $\mathrm{R} \$ 1.484,66$. No SAF 2 a pimenta-do-reino correspondeu a $66 \%$ da renda total do sistema ( $\mathrm{R} \$ 27.744,00)$, a moringa processada em pó $20 \%$ $(\mathrm{R} \$ 8.870,0)$ e a venda de mudas de pimenta-do-reino a $14 \%$ da renda total do SAF $(\mathrm{R} \$ 6.525,00)$.

Destaca-se que no SAF 1 dentre as espécies implantadas, apenas banana, cupuaçu, graviola e pimenta-do-reino obtiveram retorno financeiro até agosto de 2017 . No entanto para a espécie graviola, observou-se uma renda considerada baixa ( $\mathrm{R} \$ 286,66$ por hectare).

A pimenta-do-reino, por sua vez, apresentou os valores mais expressivos com renda bruta total de $\mathrm{R} \$ 50.135,00$ no período de dois anos de estudo, sendo, portanto, a principal cultura do SAF 1. Nesse contexto, o mês de maior venda foi em agosto de 2015 , no valor de $\mathrm{R} \$ 12.000,00$ e preço de venda $\mathrm{R} \$ 22,50$ ao quilograma de fruto seco. No mês de maior colheita da pimenta-do-reino foram contratados 10 trabalhadores para 15 dias de colheita, totalizando $\mathrm{R} \$$ 3.000,00 como despesas de mão-de-obra para esta atividade.

O SAF 2 (Figura 2) segue a mesma tendência de rentabilidade do SAF 1, sendo a pimenta-do-reino a cultura 
que impulsiona este sistema economicamente com a produção em grãos e venda de mudas no valor de $\mathrm{R} \$ 6.525,00$ (14\% da renda total do SAF 2) em dois anos de pesquisa. Assim como no SAF 1 o mês que obteve maior sucesso na renda da pimenta-do-reino foi agosto de 2015, na ordem de $\mathrm{R} \$ 25.000,00$. Nesse sistema, destaca-se ainda, a moringa processada, com renda de $\mathrm{R} \$ 8.870,00$.

A Figura 3 representa o percentual dos os custos totais em cada SAF e a participação de seus componentes onde destaca-se, com maior dispensa de valores, os custos com tratos culturais (SAF2) e insumos (SAF1). Na disposição destes custos não foram contabilizadas a depreciação de máquinas e equipamentos.

Os custos totais no SAF 1 foram $\mathrm{R} \$ 17.125,50$, com $84 \%$ $(\mathrm{R} \$ 14.641,50)$ concentrados no primeiro ano de monitoramento (ago/2015 a ago/2017). Para este sistema do valor total investido em dois anos, $40 \%$ foi gasto com insumos (fertilizante NPK 10-10-10, cama de frango e esterco de gado, materiais para irrigação como mangueiras e

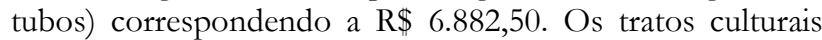
(poda, capina, coroamento, roçagem) corresponderam a $32 \%$ $(\mathrm{R} \$ 5.536,00)$ enquanto custos com colheita corresponderam a $20 \%(\mathrm{R} \$ 3.350,00)$ e, por fim, a limpeza da área correspondeu a $8 \%(\mathrm{R} \$ 1.357,00)$.

No SAF 2 os custos totalizaram R $\$ 5.121,00$. O primeiro ano de monitoramento, assim como no SAF 1, também foi o que demandou maiores recursos $(\mathrm{R} \$ 3.536,00$ - 69\% do gasto total). Já no segundo ano foram gastos $\mathrm{R} \$ 1.585,00$, correspondendo a $31 \%$ do capital investido. No valor total aplicado na área, $47 \%$ desses custos foram com tratos culturais ( $\mathrm{R} \$ 2.423,00), 35 \%$ com insumos $(\mathrm{R} \$ 1.773,00)$ e $18 \%$ de gastos com limpeza e preparo da área $(\mathrm{R} \$ 925,00)$.

Outro fato constado neste trabalho foi o acentuado uso de mão de obra para realizar atividades como limpeza e preparo de área, colheita e tratos culturais. No SAF 1 os gastos com preparo de área, tratos culturais e colheita somaram $60 \%$ do custo total do SAF, enquanto no SAF 2, o custo com mão de obra no preparo de área e limpeza, juntamente com tratos culturais, somaram $65 \%$ do referido sistema.

Com base na diferença entre receitas versus custos, observa-se que os sistemas apresentam alta rentabilidade. $\mathrm{O}$ SAF1 no período estudado apresentou renda de $\mathrm{R} \$$ $52.293,47$, tendo despesas totais de $\mathrm{R} \$ 17.125,50$, vindo a ter um saldo positivo de $\mathrm{R} \$ 35.167,97$, praticamente o dobro do valor investido. Ressalta-se, no entanto, que este fluxo de caixa apresentado não contabilizou o valor da terra e a depreciação de máquinas e equipamentos e sim, somente receitas e custos da produção agroflorestal. Já no SAF2 a renda total foi de $\mathrm{R} \$ 45.139,00$, com despesas de $\mathrm{R} \$ 5.121,00$ resultando em saldo de $\mathrm{R} \$ 36.997,00$, praticamente seis vezes o valor investido no sistema. Este produtor teve poucos gastos com mão de obra externa, tendo em vista que o serviço no SAF foi realizado com mão de obra familiar, fazendo com que as despesas do produtor do SAF2 fossem bem menores que gasto do produtor do SAF1.

A receita das atividades agrícolas realizadas na propriedade do SAF 1, porém em área externa a este sistema, no período estudado, foi de R\$1.419,50 (Figura 4). A maior parte deste valor $(75 \%)$ dessa renda foi obtida em 2016, que equivale a $\mathrm{R} \$ 1.062,50$ e $25 \%$ o ano de 2017 . Neste sistema o mês de maior renda foi abril/2016, com a venda de galinha caipira e ovos com faturamento total mensal de $\mathrm{R} \$ 500,00$, seguido de julho/2017 (R \$ 237,00) com a venda de maracujá e, por fim, setembro/2016 novamente com venda de ovos e galinha caipira, faturando $\mathrm{R} \$ 230,00$.

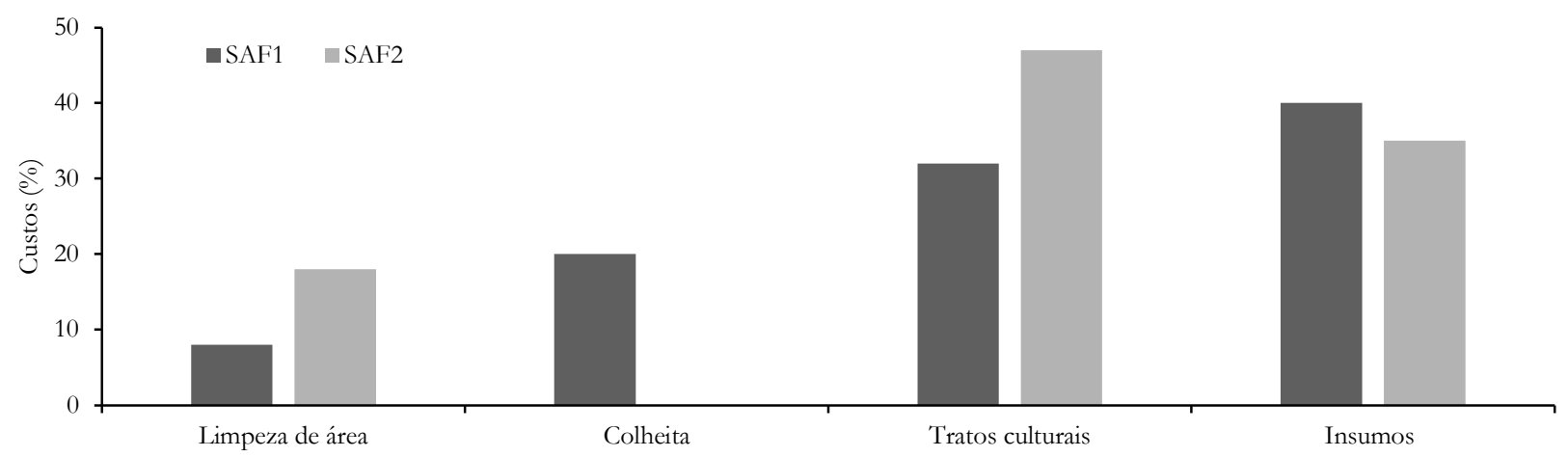

Figura 3. Percentual de custos em sistemas agroflorestais no período de 2 anos no município de Belterra, Pará. Figure 3. Percentage of costs in agroforestry systems over a 2-year period in the municipality of Belterra, Pará.

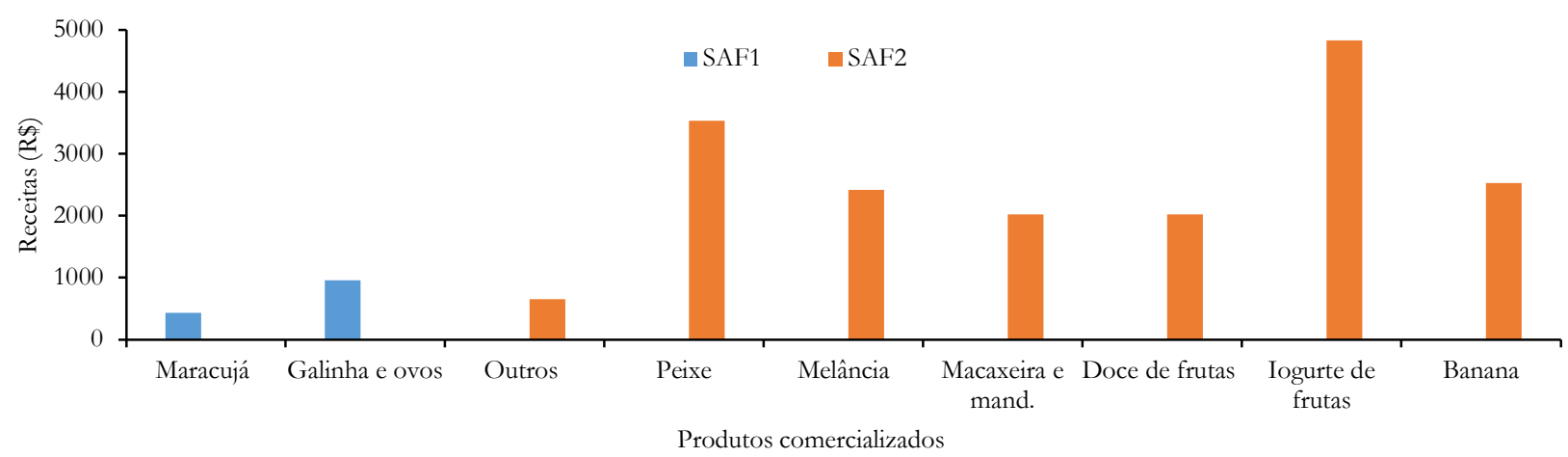

Figura 4. Renda com atividades na propriedade, exceto da atividade no sistema agroflorestal, em dois sistemas no município Belterra.

Figure 4. Income from activities on the property, except from activity in the agroforestry system, in two systems in the municipality of Belterra. 
Para a propriedade, onde está inserido o SAF2, os rendimentos com atividades, exceto no sistema agroflorestal, alcançou R $\$ 42.118,00$ no período estudado (Figura 4). Dessa renda total, $83 \%(\mathrm{R} \$ 35.072,00)$ foi obtida no segundo ano de pesquisa (Set/2016 a Ago/2017) e 17\% no primeiro ano (R\$7.046,00). Nota-se a contribuição de monoculturas nesta composição de renda com destaque para a banana e melancia, que renderam $\mathrm{R} \$ 25.380,00$ e $\mathrm{R} \$ 2.414,00$, respectivamente.

Fora do SAF 2 também foram detectadas outras receitas oriundas de subprodutos processados como iogurte e doces de frutas, com valor total de $\mathrm{R} \$ 3.320,00$ e $\mathrm{R} \$ 2.931,00$ respectivamente. Além disso, nas proximidades desse mesmo sistema, o produtor mantém uma criação de peixes que gerou rendimentos de $\mathrm{R} \$ 2.185,00$ em 2016 e $\mathrm{R} \$$ 570,00 em 2017.

Outro dado levantado foi a complementação da renda familiar através dos benefícios sociais auferidos pelo Governo Federal como Bolsa Família e Bolsa Verde, presentes junto ao produtor do SAF1. No período estudado estes benefícios corresponderam a $\mathrm{R} \$ 4.418,00$ sendo que deste total $66 \%$ foi de bolsa família $(\mathrm{R} \$ 2.918,00)$ e 33,9\% correspondeu a bolsa verde $(\mathrm{R} \$ 1.500,00)$, distribuídos da seguinte forma: em 2015 ( $\mathrm{R} \$ 1.160,00), 2016(\mathrm{R} \$ 2.274,00) \mathrm{e}$ em 2017 (R\$984,00). Esse repasse de benefícios proporciona ao produtor segurança na aquisição de bens para uso na sua propriedade.

\section{DISCUSSÃO}

A renda mensal por hectare nos SAFs 1 e 2, evidencia uma contribuição muito positiva da espécie pimenta-doreino, principalmente devido ao valor de mercado praticado para esta espécie no período estudado $(\mathrm{R} \$ 9,00$ a $\mathrm{R} \$ 25,00$ $/ \mathrm{kg}$ ). Valores semelhantes foram observados no estudo de Oliveira et al. (2017) em Tomé-Açu-PA, que ao analisar um SAF nessa região registrou para a pimenta-do-reino de preço de $\mathrm{R} \$ 35,00 / \mathrm{kg}$ em 2015 e $\mathrm{R} \$ 20,00 / \mathrm{kg}$ em 2016. Alves (2017), em seu estudo do comportamento das exportações entre 2005 a 2015, destaca o Brasil como o terceiro maior produtor mundial de pimenta-do-reino, produção de 42.312 a 80.316 t/ano, sendo inferior apenas a Vietnã e Indonésia. Neste cenário destaca-se ainda o estado do Pará como o maior produtor de pimenta-do-reino no Brasil, seguido pelos estados do Espírito Santo e Bahia.

Em relação a renda das espécies nos sistemas (SAF 1 e SAF 2), o baixo desempenho econômico do cupuaçu no período estudado pode ser explicado pelo fato da cultura ainda estar nos seus primeiros anos de produção, onde é esperado aumento da produção. Estudo de Arco-Verde (2008), realizado em Boa Vista, Roraima, mostram que o cupuaçu obteve produtividade de $39 \mathrm{~kg}$ por hectare no sexto ano de plantio, atingindo receita de $\mathrm{R} \$ 460,00$ por ha.

O valor de renda reduzido da espécie graviola presente no SAF 1, justifica-se por ser um plantio monitorado de 3 a 5 anos, visto que de acordo com Silva; Garcia (1999) a cultura da graviola só tem valores de produtividade mais incipiente a partir do terceiro ano de plantio. Outro fato registrado no presente estudo foi a ocorrência da broca da graviola, fazendo com que tivesse produção prejudicada a partir do primeiro ano. Esta patologia é considerada a praga mais prejudicial à gravioleira, pois ataca a polpa, empupa o fruto ainda na planta, ou no solo, o que acarreta frutos retorcidos com manchas irregulares (OLIVEIRA, 2011). Além disso, algumas dificuldades técnicas dificultam a produtividade da graviola como falta de insetos polinizadores nos pomares necessitando de polinização artificial (CAVALCANTE, 2000). Ainda com relação a dificuldades técnicas no cultivo de graviola, Pinto et al. (2001) afirma que a graviola é uma espécie exigente em relação água. A junção destas especificidades pode ter causado a baixa produção de graviola no SAF1.

Nos dois sistemas analisados a pimenta-do-reino do SAF 1, demonstrou retorno a curto prazo desta cultura ao produtor. Isso também foi evidenciado no estudo de Sanguino et al. (2007), ao estudar um SAFs em Tailândia-PA, onde constatou que a pimenta-do-reino apresenta elevado potencial econômico, possuindo mercado garantido já no primeiro ano de implantação do sistema produtivo. Resultados semelhantes também foram constatados por Oliveira et al. (2017), que ao analisar economicamente um SAF em Tomé-Açu, no Pará, pôde observar rápido retorno com a presença de pimenta-do-reino, ao demonstrar altas receitas já no segundo ano de implantação, na ordem de R \$ $17.500,00$ (2015) a R $\$ 40.000$ (2016).

No que diz respeito à rentabilidade dos SAFs destaca-se um cenário promissor, pois os sistemas mantêm a associação da pimenta-do-reino com espécies frutíferas perenes e florestais como cupuaçu e cumaru, estando de acordo com Mendes (2003), que destaca essa associação como tendo os melhores retornos líquidos num horizonte futuro.

No período da pesquisa (2015 a 2017) o preço da pimenta-do-reino esteve competitivo no mercado afetando diretamente as práticas e investimentos dos produtores. No entanto, em período posterior houve redução dos valores de venda o que resultou, por parte dos produtores, no cessamento da aplicação de adubação e irrigação em suas plantações. Segundo a Companhia Nacional de Abastecimento - CONAB (2019) o preço praticado para este produto, em 2019, foi de $\mathrm{R} \$ 6,08$ a $\mathrm{R} \$ 6,18$ o quilograma. De acordo com Carneiro-Junior et al. (2017), há uma relação positiva direta entre o preço da pimenta-do-reino e a quantidade ofertada, ou seja, quando o preço sobe a quantidade ofertada também se eleva. Dessa forma a grande oscilação de oferta acompanha os preços e a produção.

No SAF 2, a moringa processada gerou uma renda que representa $20 \%$ do total obtido. Essa espécie apresenta diversos usos, além de ser resistente a diversas condições edafoclimáticas, principalmente a condições de pouca disponibilidade de água (VASCONCELOS, 2013). De acordo com Silva et al. (2018a) a moringa é considerada uma espécie potencial para a suplementação alimentar humana, tendo em vista as propriedades nutricionais de seus componentes (folhas, flores e sementes) onde sua forma processada pode ser adicionada em diversas receitas de pães, bolos e saladas, se tornando uma alternativa de consumo para populações mais carentes. A moringa também representa uma forma alternativa na remoção de partícula e microrganismos em suspensão aquosa, sendo uma opção importante no processo de potalização da água (FRIGHETTO et al., 2007).

Quanto aos custos totais por sistema e participação dos seus componentes, observa-se, em ambos os SAFs, que o custo com insumos representou um percentual alto, com valores de $40 \%$ no SAF 1 e 35\% no SAF 2 . Essa tendência pode ser explicada pelo fato de os dois consórcios serem compostos majoritariamente com a cultura da pimenta-doreino que é um cultivo que requer investimento neste quesito. Estudo de Cardoso et al. (2018) sobre a viabilidade de 
pequenos cultivos de pimenta-do-reino em Tomé-Açu, Pará, mostrou que os gastos com insumos representaram $70 \%$ dos custos totais de implantação. Este fato também concorda com Homma et al. (2004), que concluíram que a cultura da pimenta-do-reino requer investimento inicial alto, pois, tratase de uma espécie exigente de nutrientes. Para Serrano (2017) o custo de implantação da cultura da pimenta-do-reino é considerado oneroso, com valores em torno de $\mathrm{R} \$ 15.000,00$ a R \$ 25.000,00/ha em função de sua exigência nutricional, necessidade de irrigação e de tutores para sustentação da planta.

O elevado uso de mão de obra destinada as atividades dos sistemas, corrobora com o que foi verificado nos SAFs estudados por Bentes-Gama et al. (2005) em Machadinho d'Oeste, RO, onde o uso de mão de obra chegou a compor $70 \%$ dos custos totais dos sistemas.

Pode-se observar que os custos totais dos SAFs ainda são altos, pois o horizonte estudado correspondeu ao terceiro a quinto ano de implantação dos sistemas. Em relação a isso Arco-Verde (2008) destaca que os maiores custos ocorrem nos três primeiros anos de implantação do SAF, por ser a fase mais onerosa. Também o estudo de Silva et al. (2018b), ao fazer a análise de viabilidade econômica de SAFs em Novo Progresso - Pará, destaca que nos três primeiros anos os maiores gastos são com preparo de área e insumos.

Além da renda obtida com os SAfs, no decorrer da pesquisa observou-se que a renda extra do produtor mantenedor do SAF1 é oriunda de atividades realizadas no quintal agroflorestal que é mantido nas redondezas da casa do proprietário. Segundo Lunz (2007) o quintal agroflorestal é também conhecido como horto caseiro ou pomar, é formado pela associação de espécies florestais, agrícolas, medicinais e ornamentais, juntamente com a criação de animais ao redor da residência, tendo como objetivo fornecer renda e serviços, sendo muito comum em pequenas propriedades rurais na Amazônia, onde as espécies frutíferas têm papel fundamental.

Como destaque de renda extra ao sistema agroflorestal tem-se, no SAF1, a venda de galinha caipira e ovos. Neste sentido Souza (2016), em estudo sobre a criação de galinhas em quintais agroflorestais, concluiu que esta atividade é uma alternativa viável para agricultores familiares, possibilitando o uso de carne e ovos para o autoconsumo, além de geração de renda com a venda desses produtos. Também se destaca a venda de maracujá nesta propriedade, onde, como citado por Almeida; Gama (2014), em levantamento sobre quintais agroflorestais em Santarém - Pará, existe demanda média de produção de maracujá pelos produtores.

A renda mensal com atividades extra ao SAF1 mostrou valores próximos ao do estudo de Miranda (2012), que ao avaliar quintais no nordeste paraense, atestou que a renda mensal dos produtores foi de $\mathrm{R} \$ 357,33$, contribuindo com a alimentação e geração de renda.

No SAF 2 o sucesso da renda da monocultura da banana pode ser explicado pelo fato de ocupar o segundo lugar no Brasil em área colhida, produção e consumo por habitante (IBGE, 2008). Historicamente a cultura da banana se destaca no Pará desde os anos 1990, com extrema relevância social e econômica para agricultores do estado, sendo que em 2017 o Pará ficou na quinta colocação como maior produtor no Brasil (IBGE, 2017).

A monocultura de melancia, que também obteve êxito na renda neste trabalho, é considerado de alta rentabilidade pois como avaliado por Ramos et al. (2015), em consorcio entre monoculturas de melancia e mandioca, atestaram valores na ordem de $\mathrm{R} \$ 8.500,00$ por hectare em dois anos de plantio.

Rendas obtidas de subprodutos processados fora dos sistemas, como ocorre no SAF 2 (iogurte e doces de frutas) são comuns em propriedades rurais, pois gera segurança alimentar e auxilia nas despesas fixas e geralmente é feito por mulheres (CANUTO, 2017).

Quanto a renda oriunda da venda de peixes, De-Sá et al. (2008), ao realizarem um diagnóstico da piscicultura praticada por pequenos produtores no baixo Acre, atestou renda

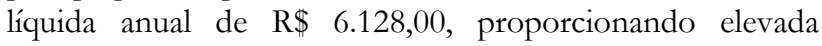
remuneração para o produtor.

Em relação a renda complementar, adquirida por meio de benefícios sociais do Governo Federal, Nascimento et al. (2016) afirmaram que o bolsa família influencia diretamente a vida de seus beneficiários e aumenta o poder aquisitivo deles. De acordo com Britto (2010), ao estudar propriedades rurais no município de Pacajá-PA, a renda oriunda do bolsa família possibilita a aquisição de bens e produtos nas atividades da unidade de produção familiar. O programa da Bolsa Verde colabora com práticas sustentáveis em propriedades rurais, além de aumentar a renda do produtor e ajudar em práticas que venham a melhorar o meio ambiente (MACIEL; KHAN, 2015) e faz uma união da geração de renda para o produtor aliadas a práticas de preservação ambiental (CALORIO; ONCALA, 2017).

\section{CONSIDERAÇÕES FINAIS}

Houve a predominância da cultura da pimenta-do-reino nos sistemas agroflorestais avaliados, o que faz com que este cultivo sustente os sistemas de forma majoritária em virtude da sua alta produtividade e excelente valor de mercado. No entanto, se evidencia a necessidade de um estudo econômico a longo prazo nos dois sistemas, de maneira a se mensurar o comportamento financeiro não só da pimenta-do-reino, mas também dos outros cultivos, que no presente estudo, ainda não estão em anos de produtividade mais acentuada.

No SAF 2 a moringa se mostrou uma espécie promissora em virtude da sua alta rentabilidade econômica e do aproveitamento de seus derivados (folhas, flores e sementes).

Os maiores custos nos SAFs 1 e 2 foram com insumos, tendo em vista a predominância da pimenta-do-reino nos sistemas, cultura que é exigente de insumos. O uso de mão de obra com preparo da área e tratos culturais foi alto nas duas propriedades e corresponderam a mais de $60 \%$ dos custos totais nos dois SAFs.

A renda com atividades, além dos SAFs 1 e 2, diversificaram e complementaram a remuneração dos produtores em suas áreas, além de terem contribuído para o autoconsumo.

Considera-se que os SAFs 1 e 2 são de extrema importância para os produtores avaliados, uma vez que geram renda e contribuem para o seu desenvolvimento social e econômico.

\section{REFERÊNCIAS}

ABDO, M. T. V. N.; VALERI, S. V.; MARTINS, A. L. M. Sistemas agroflorestais e agricultura familiar: uma parceria interessante. Revista Tecnologia \& Inovação Agropecuária, Frederico Westphalen, v. 12, p. 50-59, dez. 2008.

ALMEIDA, L. S. de; GAMA, J. R. V. Quintais agroflorestais: estrutura, composição florística e aspectos 
socioambientais em área de assentamento rural na Amazônia Brasileira. Ciência Florestal, Santa Maria, v. 24, n. 4, p. 1041-1053, 2014. DOI: https://doi.org/10.1590/1980-509820142404023.

ALVARES, C. A.; STAPE, J. L.; SENTELHAS, P. C.; GONÇALVES, J. L. M.; SPAROVEK, G. Köppen's climate classification map for Brazil. Meteorologische Zeitschrift, Stuttgart, v. 22, n. 6, p. 711-728, 2013. DOI: 10.1127 / 0941-2948 / 2013/0507

ALVES, F. P.; PAIXÃO, C. P. C.; FERREIRA, C. S.; SOUZA, L. L. de. Comportamento das exportações e produção de pimenta-do-reino-do- reino no Brasil e no Pará de 2005 À 2015. In: Congresso Internacional das Ciências Agrárias COINTER PDVAgro 2017, Anais... Natall: COINTER - PDVAgro.

ARCO-VERDE, M. F. Sustentabilidade biofísica e socioeconômica de sistemas agroflorestais na Amazônia brasileira. 2008. 188f. Tese (Doutorado em Ciências Florestais) - Universidade Federal do Paraná, Curitiba, 2008.

ARCO-VERDE, M. F.; AMARO, J. C. Análise financeira de sistemas produtivos integrados. 1 ed. Colombo: Embrapa Florestas, 2014. 74p.

BENTES-GAMA, M. M.; SILVA, M. L. da; MONTOYA, VILCAHUAMAN, L. J.; LOCATELLI, M. Análise econômica de sistemas agroflorestais na Amazônia Ocidental, Machadinho D’Oeste-RO. Revista Árvore, Viçosa, v. 29, n. 3, p. 401-411, 2005. DOI: https://doi.org/10.1590/S010067622005000300 007.

BRITTO, G. C. Prestação de Serviços Ambientais em Unidades de Produção Familiar Rurais no município de Pacajá - Território da Transamazônica - Pará - Brasil. 2010. 179f. Dissertação (Mestrado em Agricultura Familiar e Desenvolvimento Sustentável). Universidade Federal do Pará e Empresa Brasileira de Pesquisa Agropecuária - Amazônia Oriental. Belém, 2010.

CALORIO, C. M.; ONCALA, A. A. Agroextrativismo e Bolsa Verde na Política Nacional de Agroecologia e Produção Orgânica. In: SAMBUICHI, R. H. R.; MOURA, I. F. de; MATTOS, L. M. de; ÁVILA, M. L. de; SPÍNOLA, P. A. C.; SILVA, A. P. M. da. Política Nacional de Agroecologia e Produção Orgânica no Brasil:. Brasília: IPEA, 2017. p. 359-379.

CANUTO, J. C. Sistemas Agroflorestais: experiências e reflexões Brasília. 1 ed. Brasília: Embrapa, 2017. 216p.

CARNEIRO-JUNIOR, J. F. C.; LIMA, J. M. de; SILVA, A. L. P. da; NASCIMENTO, M. N. C. F. Análise de mercado da pimenta-do-reino de no período de 1990 a 2015. Tecnologia \& Ciência Agropecuária, João Pessoa, v. 11, n. 6, p. 139-145, dez. 2017.

CARDOSO, M. S. P.; GARCIA, W. S.; SILVA, I. M. da. Viabilidade Econômica da produção de Pimenta-doreino em pequena escala no município de Tomé-Açu (PA). Revista Gestão em Conhecimento, Tomé-Açu, v. 1, n. 1, p. 97-112, jan./jun. 2018.

CAVALCANTE, T. R. M. Polinizações manual e natural da gravioleira (Annona muricata L., Annonaceae). 2000. 55f. Dissertação (Mestrado em Fitotecnia) Universidade Federal de Viçosa, Viçosa, 2000.

CONAB_Companhia Nacional de Abastecimento. Disponível em:

http://sisdep.conab.gov.br/precosiagroweb/> Acesso em: 13 de dez de 2019.

CORDEIRO, A. Floresta nacional do tapajós: plano de manejo. Belterra: IBAMA, v. 1, 2004. 350 p.

DE-SÁ, C. P.; BALZON, T.; OLIVEIRA, T. J.; BAYAMA, M. M. A.; CARNEIRO-JUNIOR, J. M. C. Diagnóstico sócio-econômico da piscicultura praticada por pequenos produtores da regional do Baixo Acre. Rio Branco: Embrapa Acre, 2008. 9p. Disponível em: https://ainfo.cnptia.embrapa.br/digital/bitstream/item /141722/1/20097.pdf

FRIGHETTO, R. T. S.; FRIGHETTO, N.; SCHNEIDER, R. P.; FERNANDES-LIMA, P. C. O Potencial da Espécie Moringa oleifera (Moringaceae). I. A Planta como Fonte de Coagulante Natural no Saneamento de Águas e como Suplemento Alimentar. Revista Fitos, São Paulo, v. 3, n. 2, p. 78-88, jun. 2007.

HOMMA, A. K. O. Dinâmica dos sistemas agroflorestais: o caso da Colônia Agrícola de Tomé-Açu, Pará. Revista Instituto de Estudos Superiores da Amazônia, Belém, v. 2, n. 1/2, p. 57-65, 2004.

IBGE. Pesquisa de Orçamentos Familiares, 2008. Disponível em: Acesso em: 27 de outubro de 2019.

IBGE/PAM. Panorama Agrícola do Pará 2010/2017. SEDAP-PA.

INMET_Instituto Nacional de Meteorologia. Banco de dados meteorológicos para ensino e pesquisa BDMEP. Disponível em: <http://www.inmet.gov.br/portal/index.php?r=bdmep /bdmep>. Acesso em 12 dezembro 2016.

LUNZ, A. M. P. Quintais agroflorestais e o cultivo de espécies frutíferas na Amazônia. Revista Brasileira de Agroecologia, Dois Vizinhos, v. 2, n. 2, p. 1255-1258, 2007.

MACEDO, R. L. G. Princípios básicos para o manejo sustentável de sistemas agroflorestais. 1 ed. Lavras: UFLA/FAEP, 2000. 157p.

MACIEL, H. M.; KHAN, A. S. Política ambiental no Brasil: a implantação do programa bolsa verde. Revista IberoAmericana de Ciências Ambientais, Aracaju, v. 6, n. 1, p. 172-186, 2015. DOI: http://dx.doi.org/10.6008/SPC21796858.2015.001.0014

MENDES, F. A. T. Avaliação de modelos simulados de sistemas agroflorestais em pequenas propriedades cacaueiras selecionadas no município de Tomé-Açu, no estado do Pará. Belém-PA, 2003. Revista GEPEC, Toledo, v. 7, n. 1, p. 1-19, 2003. DOI: https://doi.org/10.48075/igepec.v7i1.300

NASCIMENTO, E. C. do; CRUZ, B. E. V. da; CALVI, M. F.; CARVALHO, J. P. L de; REIS, C. C. dos; GOMES, D. L. A influência do Programa Bolsa Família nas práticas alimentares das famílias do Território do Marajó, Pará, Brasil. Scientia Plena, Aracaju, v. 12, n. 6, p. 1-11, 2016. DOI: https://doi.org/10.14808/sci.plena.2016.069931

OLIVEIRA, M. L.; SCARAMUSSA, P. H. M.; SANTOS, A. R. S.; BENJAMIN, A. M. S. da. Análise do Custo Econômico de um Sistema Agroflorestal na comunidade Nova Betel, município de Tomé Açu, Estado do Pará. In: Congresso Internacional das Ciências Agrárias COINTER PDVAgro 2017, Anais... Natal: COINTER - PDVAgro.

OLIVEIRA, M. A. S.; JUNQUEIRA, N. T. V.; ALVES, R. T.; OLIVEIRA, J. N. S.; ICUMA, I. M.; ANDRADE, G. A. de; SILVA, J. F. e. Broca-do-fruto da graviola no

Nativa, Sinop, v. 9, n. 1, p. 92-99, jan./fev. 2021. 
Distrito Federal. Planaltina: Embrapa Cerrados, 2011. 4p. (Comunicado Técnico, 55)

PINTO, A. C. Q.; SILVA, E. M. da. Tratos culturais. Graviola. Produção: aspectos técnicos. 1 ed. Brasília: Embrapa Informação Tecnológica, 2001. 41p.

RAMOS, C. J. G.; KATO, O. R.; AZEVEDO, de C. M. B. C.; SHIMIZU, M. K. Análise Financeira do Consorcio de Melancia e Mandioca no sistema de preparo de área com corte e trituração. In: Seminário de Iniciação Científica, 19.; Seminário Pós-Graduação da Embrapa Amazônia Oriental, 3., Anais... Belém-PA, Embrapa Amazônia Oriental, 2015.

SANGUINO, A. C.; SANTANA, A. C. de; HOMMA, A.K. O.; BARROS, P. L. C. de; KATO, O. R.; AMIN, M. M. O. G. Avaliação econômica de sistemas agroflorestais no Pará. Revista de Ciências Agrárias, Belém, n. 47, p. 71 88, 2007.

SERRÃO, E. A. S.; HOMMA, A. K. O. Agriculture in the Amazon: the question of sustainability. Washington: Committee for Agriculture and Environment in the Humid Tropics, 1991. 100p.

SERRANO, L. A. L. Pimenta-do-reino: Alta rentabilidade atrai produtores para a atividade. Revista Campo \& Negócios, Uberlândia, p. 1-6, 2014. Disponível em: http://www.revistacampoenegocios.com.br/pimentado-reino-alta-rentabilidade-atrai-produtores25/08/2014. Acesso em: 13 de fev de 2019.

SILVA, S. E. L. da; GARCIA, T. B. A cultura da graviola (Annona muricata L.). Manaus: Embrapa Amazônia Ocidental, 1999. 19p.

SILVA, G. F. da; SANTANA, M. DE F. S. de; LIMA, A. K. V. DE O.; BERGAMASCO, R. PAIVA, P. M. G. SANT'ANNA, M. C. S. de; SERAFINI, M. R. BERY, C. C. de. Potencialidades da Moringa oleifera Lam. São Cristóvão: Universidade Federal de Sergipe, 2018a. 228p.

SILVA, S. U. P. da; PAULETTO, D.; MOTA, C. G. da; NASCIMENTO, G. de C. S. do; SANTOS, J. A. C. dos; RODE, R.; NOCE, R. Viabilidade Econômica de Sistemas Agroflorestais em Novo Progresso, Pará. Revista Ibero-Americana de Ciências Ambientais, v. 9, n. 6, 2018b. DOI: https://doi.org/10.6008/CBPC21796858.2018.006.0003

SILVA, L. de J; MENEGHETTI, G. A.; MORENO, A. A.; da SILVA, K. E.; PINHEIRO, J. O. C. Produção para Autoconsumo na Floresta Nacional (Flona) do Pau-Rosa, Maués, AM. In: Workshop de Pesquisa e Agricultura Familiar: Fortalecendo a Interação da Pesquisa para a Inovação e Sustentabilidade. Anais... Workshop de Pesquisa e Agricultura Familiar: Fortalecendo a Interação da Pesquisa para a Inovação e Sustentabilidade. Brasília, DF: Embrapa, 2016.
SOUZA, G. Q. de. Criação de Galinhas Caipiras em Quintais Agroflorestais em Figueirópolis D’oeste - MT. In: X Congresso Brasileiro de Sistemas Agroflorestais, 2016. Anais... Cuiabá: X Congresso Brasileiro de Sistemas Agroflorestais, 2016.

SOUZA, A. N., OLIVEIRA, A. D., SCOLFORO, J. R. S., REZENDE, J. L. P., MELLO, J. M. Viabilidade Econômica de um Sistema Agroflorestal. Cerne, Lavras, v. 13 , n. 1, p. 96-106, 2007.

VASCONCELOS, M. C. Moringa oleífera Lam. Aspectos morfométricos, fisiológicos e cultivo em gradiente de espaçamento. 2013. 65f. Dissertação (Mestrado em Agroecossistemas) - Universidade Federal de Sergipe, Aracaju, 2013.

\section{APÊNDICE A}

\section{Questionário Avaliativo dos SAFs}

1. Produtos colhidos/produzidos no mês (quantidade por área ou por planta)

2. Qual a forma de comercialização? (natura, processado, desidratado, secagem, etc)

3. Valor de venda dos produtos?

4. Compradores da produção? Existe contrato? Quantidade estipulada por mês/safra?

5. Forma de transporte e custo de transporte?

6. Origem da produção (pastagem, SAF, extrativismo, quintal, roçado, etc)

$\%$ destes produtos destinados comercio

$\%$ destes produtos destinada consumo

$\%$ destes produtos desperdiçada/estragada

7. Renda do mês: benefícios, vendas, serviços esporádicos, outras entradas. Realizou algum trabalho extra propriedade rural? Qual foi a renda?

8. Custos mensais de manutenção (poda, capina, roçagem, irrigação, troca de tutor, etc.) - anotar a quantidade de dias ou horas gastas ou combustível?

9. Adubação: se houve adubação? Qual tipo? Quantidade? Custo? Oriundo da propriedade? Ou foi troca/compra com outro proprietário

10. Houve mão de obra terceirizada? Quantos dias? Qual o valor pago? A contratação foi em razão de qual cultura?

11. Houve redução ou aumento da mão-de-obra familiar no mês?

12. Houve alguma mudança no recebimento de benefícios? 